\title{
INICIAÇÃO À PESQUISA NA EDUCAÇÃO BÁSICA: PROPOSTAS PARA APRENDER A APRENDER
}

\section{Aldeni Melo de Oliveira}

\author{
Universidade do Vale do Taquari - Univates \\ E-mail: aldeni-melo@hotmail.com
}

\section{Andreia Aparecida Guimarães Strohschoen}

Universidade do Vale do Taquari - Univates

E-mail: aaguim@univates.br

\begin{abstract}
RESUMO
O presente artigo tem como foco o 'aprender a aprender' na educação básica, por meio do desenvolvimento de projetos de pesquisa. Este estudo foi desenvolvido com alunos do 8o ano do Ensino Fundamental de uma escola estadual do município de Macapá/AP. Trata-se de uma pesquisa qualitativa, exploratória e descritiva. Utilizou-se como fundamentação teórica as ideias de autores especialistas na temática em estudo e que trazem esta como propulsora de tema gerador de discussões, mediado por pesquisas em sala de aula. Inicialmente, utilizou-se um questionário para obter as informações referentes às percepções dos alunos relacionadas à Ciência e ao Conhecimento Científico. Os alunos, em grupos, desenvolveram projetos de pesquisa, sendo esses idealizados e realizados pelos alunos, mediados pelo professor, as atividades experimentais foram preponderantes nos projetos. Os questionários e diários de bordo produzidos pelos alunos e professor foram analisados descritivamente. Com base na análise dos dados obtidos, observou-se que o trabalho com projetos de pesquisa potencializa o 'aprender a aprender' pelos estudantes. Foi possível constatar implicações importantes relacionadas ao desenvolvimento da alfabetização científica dos alunos, por meio de projetos de pesquisa.
\end{abstract}

\section{PALAVRAS-CHAVE:}

Ensino de Ciência; Projetos de pesquisa; Alfabetização científica; Ensino Fundamental.

\section{INITIATION TO RESEARCH IN BASIC EDUCATION: PROPOSALS TO LEARN TO LEARN}

\section{ABSTRACT}

This article focuses on 'learning to learn' in basic education, through the development of research projects. This study was carried out with students from the 8th year of elementary school at a state school in the city of Macapá/AP. It is a qualitative, exploratory and descriptive research. It was used as theoretical foundation the ideas of authors who are experts in the subject under study and who bring this as a driver of a theme that generates discussions, mediated by research in the classroom. Initially, a questionnaire was used to obtain information regarding students' perceptions related to Science and Scientific Knowledge. The students, in groups, developed research projects, which were idealized and carried out by the students, mediated by the teacher, the experimental activities were predominant in the projects. The questionnaires and logbooks produced by the students and the teacher were analyzed descriptively. Based on the analysis of the data obtained, it was observed that 
working with research projects enhances the 'learning to learn' by students. It was possible to see important implications related to the development of students' scientific literacy through research projects.

\section{KEYWORDS:}

Science Teaching; Research project; Scientific Literacy; Elementary School.

\section{INTRODUÇÃO}

Sabe-se que frequentemente, em aulas da unidade curricular ciências, os conteúdos são apresentados descontextualizados, fragmentados e desconexos da realidade dos estudantes. Nesse contexto, o educador deve buscar novas formas de melhorar sua relação com o conhecimento científico frente aos desafios propostos. 0 educador pode propor um trabalho que possibilita redimensionar e ampliar os códigos e conceitos em Ciências. Pode propor um trabalho que possibilita o desenvolvimento de habilidades e competências pelos alunos, com a intenção de construir uma educação sólida em seu ambiente de aprendizado (SILVA, 2008).

Entende-se que aprender não é 'estocar' informações, mas transformar, reestruturar o sistema de compreensão do mundo (ANTUNES, 2012). Quando a prática pedagógica se inspira nesse pressuposto, a docência se apresenta interligada à pesquisa, e a educação a uma ação-reflexão-ação, essencialmente humana, que de acordo com Demo (2010), possibilita que os alunos se tornem cidadãos críticos e que saibam pensar e agir socialmente.

Considerando-se a alfabetização científica em sala de aula, entende-se que o ensino de Ciências necessita ser crítico e reflexivo. Nesse sentido, as situações utilizadas para um trabalho contemplando a alfabetização científica devem estar em sintonia com a realidade cotidiana, para que por meio do conhecimento, o aluno se insira e intervenha no mundo sócio-político, promovendo a responsabilidade e a participação cidadã. Nessa perspectiva, a educação para a alfabetização científica tem 
como objeto agregar situações da vida real ao currículo escolar, transpondo as limitações tradicionais (CHASSOT, 2011).

Corroborando, Demo (2003) ressalta que a vida é um espaço naturalmente educativo, mas explicita que a educação tipicamente escolar pode ocorrer por meio da pesquisa. Em sala de aula, a pesquisa possibilita desenvolver a autonomia e a criatividade ao divergir a opinião do sujeito histórico, participativo e crítico. Para Freire (2000), a pesquisa é um eterno reconhecer e comunicar as novidades.

Em relação às concepções atuais sobre a natureza e a epistemologia das ciências, há autores que defendem o conhecimento científico como sendo resultado de um processo histórico e social. Sendo assim, a Ciência não pode ser construída sem a dimensão processual ou procedimental dos sujeitos. Mesmo havendo dificuldades e limitações dos alunos no domínio dos procedimentos científicos e em seus aprendizados, nota-se que há necessidade de viabilizar o aprender a fazer ciência. Vale dizer que também é importante repensar o ambiente escolar e colocar o aluno como sujeito do processo e parceiro na construção do conhecimento, de modo que faça uso das suas próprias elaborações para compreender o mundo. Nesse contexto, o presente estudo está relacionado com o desenvolvimento de uma postura científica comprometida com os educandos, possibilitando participar e compreender a sociedade, usando preceitos de leitura e interpretação do mundo, como propõe a alfabetização científica (CHASSOT, 2011).

Sabe-se que é um desafio da escola pública brasileira em garantir uma educação de qualidade. Urge oferecer e proporcionar uma instrumentalização técnica, científica, crítica e criativa para que a escola possa cumprir com a sua responsabilidade social que é a formação plena do educando e a construção de uma sociedade justa e solidária, conforme determinado pela Constituição Brasileira e pela Lei de Diretrizes e Bases da Educação Nacional (BRASIL, 1996). 
Em conformidade com isto, entende-se que já não é mais possível desenvolver o trabalho na sala de aula com qualquer tipo de currículo. O currículo deve ser plural, para que o aluno possa explorar os meios que possibilitam transformações sociológicas, afetivas, cognitivas e pedagógicas que implicam também transformação no agir, fazer, dizer, pensar e sentir do aprendiz. Nesse aspecto, uma possibilidade é trabalhar visando a formação do cidadão crítico é a pesquisa em sala de aula. Estudos apontam que a pesquisa desenvolvida em sala de aula pode proporcionar o acesso a noções científicas que favorecem o ensino e a aprendizagem. Dentro da perspectiva do trabalho com pesquisa, se concretizará o aprender a aprender, que de acordo com Pozo e Crespo (2009, p. 47), "é uma das metas essenciais da educação, devendo ser desenvolvida em todas as áreas e níveis".

Segundo Hernandez (1998) os fatos podem ser ensinados por meio de projetos, basta que se tenha uma dúvida inicial e que se comece a pesquisar e buscar evidências sobre o assunto. Salienta que os projetos de trabalho aproximam a escola e o aluno e favorecem o olhar crítico e o espírito investigativo. Nesse sentido, repensar as aulas de ciências no Ensino Fundamental, torna-se importante e fundamental, a partir de metodologias propostas e capazes de promover o ensino de forma mais crítica, significativa e prazerosa, sendo possível uma qualificação nos processos de ensino e de aprendizagem dos alunos.

Hermínio (2011) salienta que é fundamental dar ao aluno a oportunidade de aprender os conteúdos na perspectiva da alfabetização científica, de modo que isso contribua para a formação de um cidadão participativo e comprometido com as questões sociais de seu tempo. Considerando-se isto, Millar (2003) salienta que o ensino de ciências é um meio para a concepção integral da pessoa como cidadão, pois permite optar por aquilo que é bom para si e para a natureza. De acordo com este autor, apesar da importância da alfabetização científica para a construção da cidadania efetiva, pouco conhecimento científico tem sido assimilado e compreendido pela 
maior parte dos alunos que se encontram no Ensino Fundamental. Tal situação pode estar relacionada com um currículo e metodologias que não aguçam o espírito científico dos alunos (MILLAR, 2003).

No pensamento de Chassot (2011), ao dispor de conhecimentos científicos e tecnológicos, o indivíduo pode questionar e reconstruir problemas, frente ás complexas relações entre ciência e sociedade.

Assim como exige-se que os alfabetizados em línguasmaterna sejam cidadãs e cidadãos críticos, em oposição, políticos, seria desejável que os alfabetizados cientificamente não apenas tivessem facilitada a leitura do mundo em que vivem, mas entendessem as necessidades de transformá-lo, e transformá-lo para melhor (CHASSOT, 2011, p. 62).

A alfabetização científica desenvolve no indivíduo a competência de construir seu pensamento de maneira lógica, além de auxiliar na construção de uma sensibilidade mais crítica em relação ao mundo que o cerca. Para Días, Alonso e Mas (2003) a alfabetização científica se constitui como uma prática que se desenvolve gradualmente e que deve estar conexa às características sociais e culturais do indivíduo. Hoje, se convive mais intensamente com a ciência, a tecnologia e seus elementos. Assim, a alfabetização científica, deve se estender para além do vocabulário, deve-se haver a preocupação em levar os alunos a uma compreensão acerca dos efeitos ciência e tecnologia na sua vida pessoal e social (CHASSOT, 2011).

Segundo Demo (2003) há necessidade de se questionar como aprendemos fazer Ciência, em como adquirimos os conceitos e o espírito científico. Contudo, Pozo e Crespo (2009), explicitam que a compreensão do fazer ciência requer uma prática mais contínua, com ideias prévias dos sujeitos, que devem ser ativadas e submetidas a conflito para serem mudadas. Desse modo a pesquisa em sala de aula torna-se a via para fazer ciência.

A pesquisa em sala de aula é uma das maneiras de envolver os sujeitos, alunos e professores, num processo de questionamento do discurso, das verdades implícitas e explicitas nas formações discursivas, propiciando a partir disso a 
construção de argumentos que levem a novas verdades. Envolver-se nesse processo é acreditar que a realidade não é pronta, mas que se constitui a partir de uma construção humana (MORAES; LIMA, 2004, p. 10).

Posto isto, depreende-se então, que a pesquisa em sala de aula propicia a argumentação e busca de respostas que contribuirão para a construção do conhecimento ou reconstrução daquele já adquirido.

A pesquisa em sala de aula pode ser compreendida como um movimento dialético, em espiral, que se inicia com o questionar dos estados do ser, fazer e conhecer dos participantes, construindo-se a partir disso, novos argumentos que possibilitam atingir novos patamares desse ser, fazer e conhecer, estágios esses então comunicados a todos os participantes do processo (MORAES; LIMA, 2004, p. 11).

Além do exposto, os autores ainda apontam os três pontos relevantes relacionados à pesquisa em sala de aula que são o questionar, ou seja, a construção de argumentos e a comunicação dos fatos. O questionar, a dúvida, o problema desencadeiam uma procura, que leva a um direcionamento convergente para encontrar soluções. Precisa-se ter noção da importância da pergunta como o direcionamento inicial da pesquisa (MORAES; LIMA, 2004).

Produzir argumentos é envolver-se numa produção. É ir aos livros, é contactar pessoas, é realizar experimentos. É também analisar e interpretar diferentes ideias e pontos de vista. É, finalmente, expressar os resultados em forma de uma produção, geralmente escrita (MORAES; LIMA, 2004, p. 17).

Estes autores enfatizam também que é importante que ele mesmo problematize sua realidade, pois só assim as perguntas terão sentido para ele, já que necessariamente partirão de seu conhecimento anterior (MORAES; LIMA, 2004). Desta forma, "tomar consciência do que somos e do que pensamos é um momento inicial que precede qualquer questionamento (MORAES; LIMA, 2004, p. 13).

Pozo e Crespo (2009) expõem que a atitude de indagação e experimentação são inerentes às crianças. Assim, no que se refere à pesquisa em sala de aula, o que deve ser feito é alimentar a curiosidade já existente nas crianças e fazer com que isto seja mantido vivo, enriquecido com a investigação e o questionamento adequado para 
aproximação da realidade. Segundo os autores, deve ser trabalhada a aquisição de procedimentos que contribuem para aprender a aprender e a fazer ciência. Afirmam, ainda, que os alunos vivem numa sociedade em que os conhecimentos e as ações formativas modificam rapidamente, sendo essencial que os futuros cidadãos sejam alunos decididos e flexíveis, que possam contar com procedimentos e aptidões de aprendizagem que Ihes permitam aprender de modo contextualizado (POZO; CRESPO, 2009).

A pesquisa em sala de aula é o momento da produção propriamente dita e o questionamento é a mola propulsora. É a partir do questionar que professores e alunos devem se movimentar em direção a novos conhecimentos. A pesquisa em sala de aula ainda envolve outros aspectos do fazer científico que vai além da leitura e da análise de dados. Os sujeitos precisam documentar os fatos novos, submeter à discussão critica e divulgar os resultados dos projetos de pesquisas, surgindo assim, a comunicação dos fatos observados e analisados (MORAES; LIMA, 2004). Para que o trabalho de pesquisa em sala de aula tenha uma fluência significativa, entende-se que o professor também deve ser um pesquisador, para fazer setnido o ensinar pela pesquisa.

Educar pela pesquisa tem como condição essencial primeira que o profissional da educação seja pesquisador, ou seja, maneje a pesquisa como princípio científico e educativo e a tenha como atitude cotidiana. Não é o caso fazer dele um pesquisador "profissional", sobretudo na educação básica, já que não a cultiva em si, mas como instrumento principal do processo educativo. Não se busca um "profissional da pesquisa", mas um profissional da educação pela pesquisa. Decorre, pois, a necessidade de mudar a definição do professor como perito em aula, já que a aula que apenas ensina a copiar é absoluta imperícia (DEMO, 2003, p. 2).

Neste sentido, Demo (2003) reafirma que é desafiador educar pela pesquisa. Destaca que dentro das concepções modernas, o professor deve se colocar, essencialmente, como um orientador do processo de questionamento reconstrutivo do aluno, usando o ensinar como algo decorrente da pesquisa. 
Partindo-se destes pressupostos, o objetivo geral da pesquisa foi analisar implicações da inserção de estudantes em projetos de pesquisa almejando potencializar o 'aprender a aprender' na educação básica. De modo específico objetivou-se também investigar as concepções de ciências e de pesquisa dos estudantes do 8o ano do Ensino Fundamental de uma escola estadual do município de Macapá/AP, além de sensibilizá-los quanto ao processo de iniciação e alfabetização científica por meio de projetos de pesquisa.

\section{Percurso Metodológico}

O presente relato está inserido numa pesquisa realizada na cidade de Macapá/AP, numa escola pública que atende discentes do 6a ao 9a ano, dentre eles crianças e adolescentes com idade de 10 a 15 anos. A escola está localizada na zona sul da cidade, mas atende também a alunos da zona norte. A pesquisa teve anuência da Secretaria de Estado e Educação do Amapá - SEED e autorização da direção da escola. Também foi disponibilizado aos alunos o Termo de Consentimento Livre e Esclarecido - TCLE, para ser assinado pelos pais e responsáveis, autorizando a participação na pesquisa. Para o desenvolvimento das atividades de pesquisa foram seguidas às recomendações da Resolução CNS no 466/2012 que preceitua a ética em pesquisa com seres humanos (BRASIL, 2012).

As atividades aqui descritas referem-se a um recorte do projeto de pesquisa maior. Foi realizada no ano de 2014, com os 18 alunos da turma do 8 ano do Ensino Fundamental, considerando-se como base da educação escolar a pesquisa, visando uma sensibilização estudantes relacionada ao processo de iniciação científica e participação em projeto de pesquisa, com foco metodológico no aprender a aprender investigativo. Apresenta abordagem qualitativa, exploratória e descritiva.

Para investigar as concepções de ciências e de pesquisa dos estudantes do oitavo ano, foi utilizado um questionário baseado no modelo internacional ROSE - The 
Relevance of Science Education (ROSE, 2004). Tal modelo é resultante de um projeto de pesquisa comparativa internacional, que busca iluminar os fatores vistos pelos estudantes como importantes no aprendizado de ciência e tecnologia. Este questionário serviu como uma sondagem a cerca do conhecimento dos alunos quanto à investigação científica.

O questionário ROSE foi traduzido da Língua Inglesa e realizado uma adequação em uma versão para a Língua Portuguesa. Na adequação, foram organizadas seções, cada uma com direcionamento para interesses distintos dos alunos, em específico, o que o aluno gostaria de aprender, seu futuro emprego, os desafios ambientais, as aulas de Ciências, opiniões sobre ciências e a tecnologia, experiências fora da escola e religiosidade. Realizou-se um recorte deste questionário com uma seleção de perguntas baseadas no conteúdo programático da 8 a ano e relevâncias locais. 0 questionário adaptado pelos pesquisadores deste estudo foi disponibilizado e respondido pelos alunos durante uma aula de ciências com orientação e acompanhamento do professor titular da turma e do pesquisador. Com base no perfil observado foram elaboradas as estratégias para o desenvolvimento dos projetos de pesquisa com os 18 estudantes do 8 a ano da escola estadual, local de desenvolvimento da pesquisa. Com o questionário buscou-se conhecer as concepções dos estudantes, relacionada à Ciência e ao Conhecimento Científico.

Após a aplicação do questionário foram realizadas atividades de intervenção nesta turma de alunos. Durante o desenvolvimento destas atividades foi utilizado, pelo professor de Ciências e pelos alunos, um Diário de Bordo, no qual foram registradas e acompanhadas as observações das atividades desenvolvidas com os alunos. Além disso, o diário de bordo foi utilizado para análise da pesquisa e para a elaboração dos relatórios dos projetos dos alunos. 
As atividades foram desenvolvidas pelos alunos organizados em equipes para iniciar os projetos de pesquisa. Para construir o projeto de pesquisa e interagir durante as reuniões as equipes utilizaram as redes sociais para a busca e análise das problemáticas, refletir sobre a pesquisa e estabelecer comparativos na evolução do trabalho. Foram trabalhadas as problemáticas e as hipóteses durante as aulas, dando possibilidade aos alunos fazerem seus questionamentos. No contra turno foram realizados os testes que necessitavam de um tempo maior, imprescindível para os resultados e discussão de cada projeto. As reuniões, as análises investigativas e os experimentos aconteceram no laboratório de ciências da escola. As equipes de pesquisa participaram de reuniões semanais com duração de 2 horas-aulas, sendo um total de 18 reuniões, durante o primeiro semestre de 2014. Os grupos foram denominados Grupo 01, Grupo 02 e Grupo 03 para identificação das atividades de cada projeto de pesquisa.

Os alunos utilizaram um fichário para os registros fotográficos e um diário de bordo para registros referentes às atividades. Os alunos também elaboraram mapas conceituais (MOREIRA; BUCHWEITZ, 1993) antes, durante e após os resultados obtidos, a fim de analisar as dúvidas temporárias e as certezas provisórias observadas, buscando potencializar o 'aprender a aprender' por eles. As respostas dos questionários e os diários de bordo foram analisados descritivamente (PATTON, 2015).

\section{RESUlTAdOS E DisCUSSÃO}

Analisando-se o questionário realizado com os alunos, no que diz respeito ao querer aprender, observou-se que $85 \%$ dos alunos entrevistados têm interesse em saber como o corpo humano é feito e funciona. Outros $80 \%$ mencionaram acerca de como manter o seu corpo forte e em boa condição física. Para Carmo Junior (2005) o grande interesse por entender o corpo está relacionado à compreensão de corpo e a alma serem componentes do princípio vital que acalora os homens. Para Foucault 
(1979), o homem passou a cultuar a si próprio, assim o interesse dos alunos pelo estudo do corpo pode estar associado a esta questão. Outros $85 \%$ dos alunos mostraram interesse em querer aprender a possibilidade de vida fora do planeta. Já $66 \%$ dos alunos disseram ter interesse em querer saber como funcionam objetos tais como o rádio e a televisão. Os alunos, num percentual de $89 \%$ demonstraram curiosidade em saber como o corpo cresce e desenvolve. Verificou-se que $72 \%$ dos mostraram preocupação com o que se pode fazer para assegurar o ar limpo e água potável e 60\%, a preocupação de como a energia pode ser poupada e usada de forma eficaz.

Com relação às aulas de ciências, $82 \%$ afirmaram que consideram o componente curricular interessante, porém $68 \%$ não gostariam de ser cientistas. Verificou-se ainda, que $76 \%$ consideram as aulas de ciências de grande importância, assegurando que com a ciência que aprendem na escola podem melhorar as suas oportunidades de carreira. A partir disso, constatou-e que a disciplina ciências, é considerada interessante e, 71\% dos alunos entrevistados afirmam que os conhecimentos que adquirem em ciências serão úteis para sua vida. Com a análise do questionário foi possível fazer uma espécie de fotografia do ensino de Ciências, e evidenciou o interesse pelo fazer ciências por parte de alguns alunos. Com a discussão da análise, outros aspectos foram apontados e discutidos pelos alunos, gerando assim, o direcionamento para a elaboração e desenvolvimento de três projetos de pesquisa, pelos alunos.

Inicialmente, os alunos elaboraram mapas conceituais dentro das primeiras ideias que formalizaram para os projetos de pesquisa, o que notou ser importante para uma visualização daquilo que até então era apenas pensamento, confirmando os estudos propostos por Souza e Boruchovitich (2010).

No que se refere aos projetos, O Grupo 1 explorou a ciência e a tecnologia como forma de ajudar os pobres e buscou analisar as problemáticas ambientais. Já Grupo 02 
explorou questões relacionadas à natureza, funcionalidades do corpo humano, saúde e questões ambientais. O Grupo 03 analisou soluções para os problemas ambientais focando situações que cada um pode dar como contribuição significativa para a proteção do ambiente.

O projeto elaborado pelo Grupo 01 tinha o objetivo de confeccionar um protótipo com material alternativo para realizar a dessalinização da água. O Grupo 02 elaborou um projeto com o objetivo de construir um protótipo que possa comprovar a possibilidade do cultivo de hortaliças em ambientes modernos e também de palafitas de forma empreendedora e sustentável. Além de ampliar uma nova visão de cultura e alimentação saudável. O Grupo 03 apresentou um projeto com o objetivo de analisar as características e propriedades físico/químicas e microbiológicas dos resíduos orgânicos do Cocos nucifera (L.) e das folhas secas para produção de materiais alternativos com funcionalidades diárias.

Foram construídos modelos de simulação para as atividades de cada grupo de estudos usando materiais alternativos com resíduos sólidos coletados na comunidade que poderiam mostrar a dinâmica do que foi investigado. Após esta etapa do projeto, foi usado o diário de bordo das equipes como estratégias de ação e análise descritiva da amostra, analisando os avanços do grupo a partir de suas investigações e registros. Buscando uma resposta para as questões-problemas os alunos idealizaram e esboçaram alguns modelos. Depois de discutirem e realizarem pesquisas em diferentes fontes optaram por construir aquele modelo que julgaram ser o mais eficiente para a situação.

O Grupo 01 apresentou a seguinte problemática: Frente à disponibilidade de água salobra e salgada, considerando a escassez de água potável para suprir as necessidades básicas dos habitantes, o aproveitamento dos recursos naturais de modo economicamente sustentável e o isolamento geográfico da região, questiona-se: "é 
possível construir um dessalinizador que utilize energia solar com materiais alternativos, de baixo custo, sustentável e adequado para auxiliar no abastecimento de água doce dos moradores do Distrito do Sucuriju/AP?" Este grupoconstruiu o modelo de simulação (re) utilizando materiais alternativos e de baixo custo disponíveis em lojas especializadas. Para a construção do protótipo, os alunos utilizaram vidro cortado em 04 triângulos isósceles com lados $0,57 \mathrm{~m}$, base $0,50 \mathrm{~m}$ e altura de $0,37 \mathrm{~m}$, unidos para formar uma pirâmide quadrada com 0,3 m de altura e volume equivalente a 0,13 m3. Uma base retangular de 0,02m3foi acoplada à pirâmide retangular e suspensa utilizando as peças de madeira como base (Fig. 1).

Na prática, o aquecimento suplementar foi produzido pelo conjunto de espelhos embutidos no protetor da estrutura plana, posicionado nos lados do sistema de dessalinização para canalizar a radiação eletromagnética para a superfície inferior, o qual converge os raios solares ocasionando temperaturas maiores que posteriormente divergiem no recipiente, que contém a água salgada - um dispositivo no sentido declive de vidro ou acrílico na parte superior realiza a coleta de condensação.

Figura 1: Protótipo confeccionado pelos estudantes do $\mathrm{G1}$ da $8^{\mathrm{a}}$ série (re) utilizando materiais alternativos. Fonte: autores, 2014.

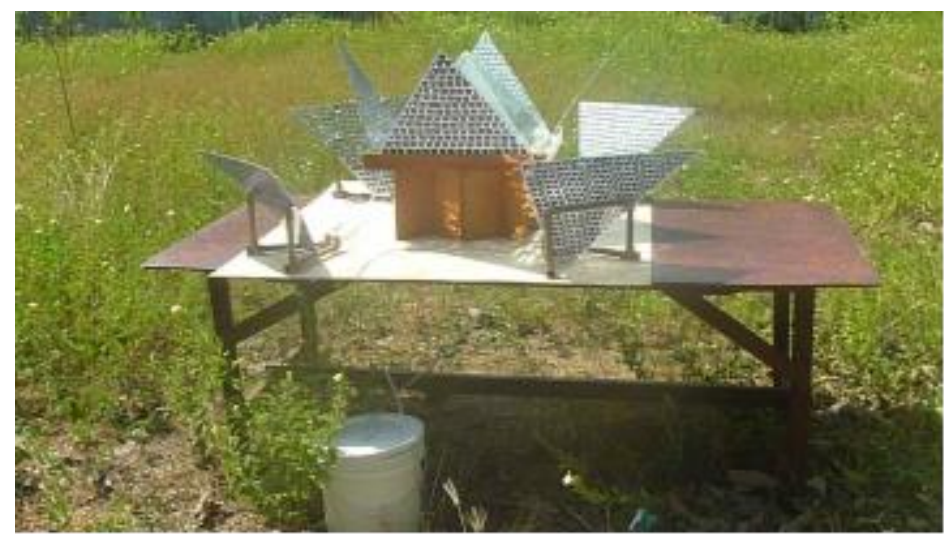

Analisando o projeto de pesquisa do Grupo 01, foi notável a utilização do método científico e o resultado obtido com o experimento foi aceitável, pois foi realizada a análise físico-química da amostra da água dessalinizada, e esta pode ser usada para 
fins domésticos e com pequenas alterações de ph pode ser utilizada para consumo. $\mathrm{O}$ resultado evidencia, portanto, que o protótipo tem potencial para amenizar a escassez de água em localidades com tal problemática.

Para o Grupo 02 a problemática foi: percebendo que as pessoas estão adoecendo cada vez mais jovens, fez-se necessário discutir os meios que podem ser utilizados para melhorar tal situação. Constatou-se que as hortaliças, tão importantes para o organismo humano, estão deixando de fazer parte da mesa do brasileiro. Além disso, a economia de água e o aumento da procura por alimentos sem agentes químicos são questões importantes levantadas no desenvolvimento deste projeto. Interroga-se: "de que forma desenvolver em pequenos espaços o cultivo de hortaliças de forma sustentável e com foco empreendedor?" Considerando-se isto, a partir das ideias estruturadas em desenhos produzidos pelos alunos, o Grupo 02, desenvolveu um protótipo de uma horta sustentável em pequeno ambiente. Os alunos esboçaram um modelo que depois de uma discutssão foi melhorado e construído. Para a construção utilizaram duas chapas de madeira compensada cortada no formato de um retângulo, com lados medindo $0,8 \mathrm{~m} \times 1,00 \mathrm{~m}$, que serviu como base da horta. Ao topo da base foram colocados recipientes como reservatório de água e anexado a eles o cultivo de modo hidropônicco. Deste reservatório foi feita uma conexão que leva a água para a segunda parte da horta (Fig. 2).

Da segunda parte do protótipo a água é encaminhada para o terceiro item que recebe o restante da água e direciona para o filtro que está encaixado na parte final. Foram acrescentados pedaços de espelhos por acreditar que pelo fato das plantas serem autótrofoas, necessitariam além da água, uma fonte de luz. Com este pensamento por parte dos alunos, nota-se a cientificidade estava presente, pois pensaram que o melhor desenvolvimento das hortaliças ocorreria se absorvessem mais raios solares. No que se refere à compostagem da terra para o plantio baseou-se na mistura de cascas de banana, mamão, maracujá e de ovos. 
Figura 2: Estrutura real do protótipo com o cultivo das hortaliças, confeccionado pelos estudantes do G1 da 8a série. Fonte: autores, 2014.

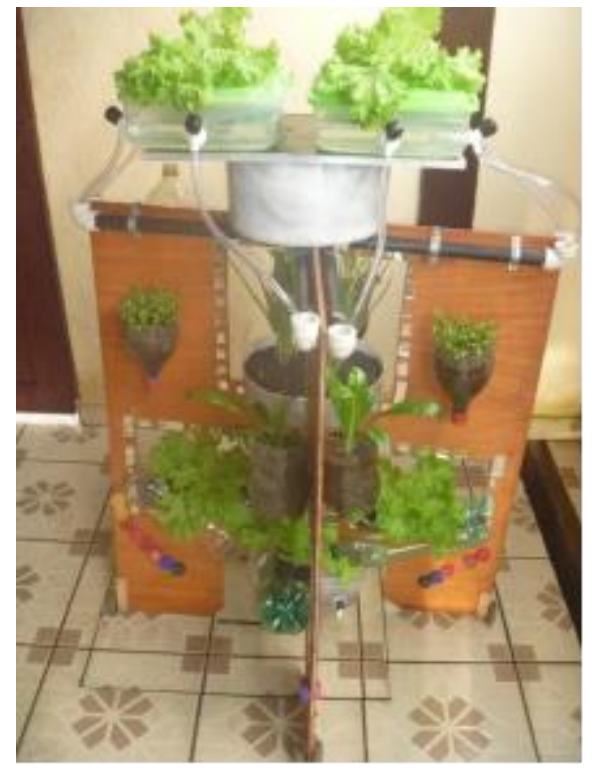

O grupo ainda trabalhou com a noção de quantidade de hortaliças produzidas em um curto espaço de tempo e pelo protótipo proposto em seu projeto de pesquisa. Com o experimento notaram que é possível ter hortaliças para o consumo de um mês para uma família com quatro membros, o que dá um resultado de uma economia de $\mathrm{R} \$ 2,90$ por dia, $\mathrm{R} \$ \mathbf{8 7 , 0 0}$ por mês e $\mathrm{R} \$ 1.044,00$ por ano, com a possibilidade ainda, de gerar fonte de renda. Com este projeto foi possível analisar que há possibilidade viável do protótipo construído, o que leva a pensar na questão do empreendedorismo ou de ações de políticas públicas para o levar a ideia à população carente.

E por fim o Grupo 03 tinha a seguinte indagação: “É natural as plantas darem furtos e soltarem folhas que já não servem para fotossíntese, estas folhas secas se acumularem nos quintais, assim como também as sobras do coco em diferentes ambientes turísticos no Brasil, então surge o grande problema para o planeta, pois é gerada muita matéria orgânica. No município de Macapá/AP as Secretarias Municipais de Manutenção Urbanística (SEMAST) e da Administração (SEMAD) afirmam que este material não é considerado lixo doméstico para ser recolhido para os lixões. É muito difícil encontrar propostas de reciclagem e/ou formas de reaproveitar este tipo de 
matéria orgânica. Então, questiona-se, de que forma transformar este tipo de material orgânico em um projeto de pesquisa que envolva estes matérias em funcionalidades diárias?" Este grupo optou por não trabalhar com esboços, mas explorou as possibilidades de utilização do coco verde (Cocos nucifera). Pela análise das características e propriedades físico-químicas e microbiológicas dos resíduos orgânicos do Cocos nucifera conseguiu como resultado a produção de: biocarvão (carvão vegetal), detergentes, sabão sólido, capa de caderno, mantas e telas para proteção do solo, isolamento acústico, substrato, fabricação de vasos e outros materiais (Fig. 3 e 4).

O trabalho deste grupo também utilizou o método científico. Na análise dos alunos, os produtos que surgem tendo como fonte de matéria-prima o referido coco têm aplicabilidades diversas no cotidiano. Observaram que são materiais que podem ser usados por todos os públicos e todas as idades e gêneros. Também destacou que a utilização do coco pode gerar fonte de renda, uma possibilidade viável de empreendedorismo.

Figura 3: Experimentos com fibra de coco Cocos nucifera, confeccionado pelos estudantes do G1 da 8a série. Fonte: autores, 2014.

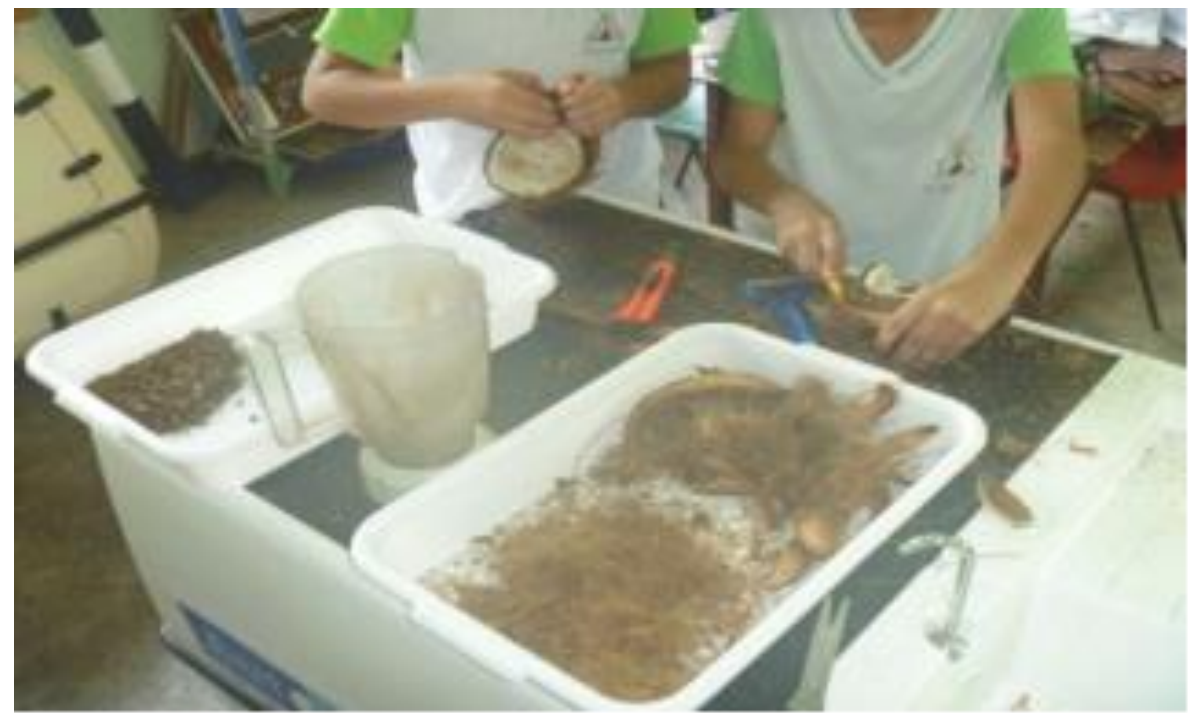


Figuras 4: Produção de sabão a partir do coco Cocos nucifera. Fonte: autores, 2014.

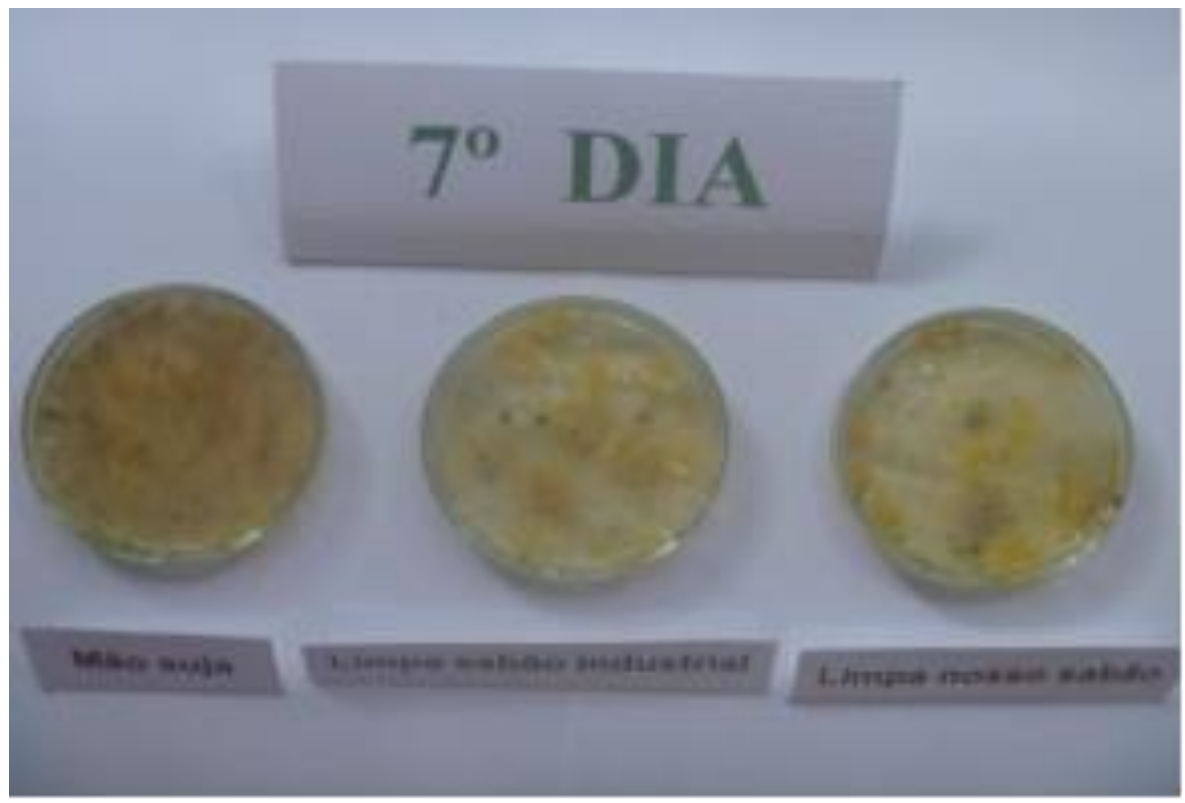

Notou-se que os alunos consideraram as atividades experimentais empíricocientíficas desenvolvidas importantes. Constatou-se que os objetivos do grupo foram alcançados, pois a questão da sustentabilidade, estava em concordância com projeto deles. Constatou-se que os alunos utilizaram o conhecimento prévio para estabelecerem associações, para conseguirem encontrar formas de desenvolvimento que atenda às necessidades do tempo presente pensando em não comprometer às próximas gerações.

Por fim, cada grupo decidiu nomear o projeto e com o auxílio do professor realizaram a nomeação dos seus projetos de pesquisa. O Grupo 01 nomeou o projeto de "Construção sustentável de um modelo de dessalinizador com aquecimento suplementar: uma proposta socioambiental". O Grupo 02 deu o nome de "Projeto Ecohorta: Um estudo de atividades experimentais" e, o Grupo 03 nomeou o projeto 
de "Cocos nucifera: Reaproveitamento de resíduos orgânicos para aplicações de funcionalidades diárias".

De modo geral, foi perceptível o envolvimento dos alunos na intervenção. Observou-se que conseguiram entender a importância de um projeto de Ciências. Além de terem atribuído às atividades experimentais grande relevância, o que é fator importante no método científico. Em suas pesquisas estavam presentes preocupações com questões socioambientais e a ideia de que por meio dos projetos de pesquisa podem realizar investigações e ter a chance de comunicar os fatos, procedimentos e resultados. Com isso fica evidente que no 'aprender a aprender' há possibilidade dos envolvidos serem os protagonistas da construção do conhecimento e conviverem com conceitos e valores científicos em suas próprias observações.

\section{CONSIDERAÇÕES FINAIS}

O trabalho com foco no aprender a aprender tem evidente relevância para os processos de ensino e aprendizagem. Com a realização das atividades nesta pesquisa foi possível constatar implicações importantes relacionadas à inserção de estudantes em de projeto de pesquisa, almejando o desenvolvimento da alfabetização científica destes. Notou-se que a alfabetização científica pode ser tida como propulsora de tema gerador de discussões, mediado por pesquisas em sala de aula. Vale ressaltar que é desafiador ensinar pela pesquisa, mas animador quando se percebe que os alunos demonstram interesse e satisfação para aprenderem a a partir do momento que começam obter resultados a com suas atividades experimentais dos projetos.

As atividades da pesquisa também possibilitaram entender que as aulas de ciências podem se tornar atraentes para os alunos quando estão associadas a investigação e realização de experimentos. Notou-se que até o erro foi importante para os alunos, pois possibilitou melhoria nos projetos e na integração com os demais grupos. 
Desta forma, pode-se afirmar que o trabalho com projetos de pesquisa potencializa o 'aprender a aprender' pelos estudantes. Foi possível constatar implicações importantes relacionadas ao desenvolvimento da alfabetização científica dos alunos, por meio do desenvolvimento dos projetos de pesquisa, pois trabalharam com questões científicas fazendo relação com o cotidiano. Acredita-se que desenvolver atividades de iniciação com alunos do Ensino Fundamental tem resultado significativo e pode trazer melhoria para os processos de ensino e de aprendizagem. Enfim, precisamos superar barreiras diante de um modelo de educação ainda muito tradicional. Não devemos esquecer que o professor ainda é peça essencial para instigar a busca por descobertas e respostas para as indagações que contribuem para uma aprendizagem efetiva. 


\section{REFERÊNCIAS}

ANTUNES, C. Como desenvolver as competências em sala de aula. 10 ed. Vozes: Petrópolis, Rio de Janeiro, 2012.

BRASIL. Lei de Diretrizes e Bases da Educação Nacional. Lei número 9394, 20 de dezembro de 1996.

BRASIL, Resolução no 466, de 12 dezembro de 2012. Diretrizes e Normas Regulamentadoras de Pesquisas Envolvendo Seres Humanos. Disponível em:<http://conselho.saude.gov.br/resolucoes /2012/Reso466.pdf>. Acessado em: 30 de mar. 2017.

CARMO Jr., W.do. Dimensões filosóficas da educação física. Rio de Janeiro: Guanabara/Koogan, 2005.

CHASSOT, A. Alfabetização científica. 5. ed. ljuí: Editora Unijuí, 2011.

DEMO, P. Educar pela pesquisa. 6. ed. São Paulo: Autores Associados Ltda, 2003. . Educação e Alfabetização Científica. Campinas: Editora Papirus, 2010.

DIAS, J.A.A.; ALONSO, A.V.; MAS, M.A.M. Papel de la Educación CTS en una Alfabetización Científica y Tecnológica para todas las Personas. Revista Electrónica de Enseñanza de las Ciencias, v.2, n.2, 2003.

FOUCAULT, M. Microfísica do poder. 11. ed. Rio de Janeiro: Graal, 1979.

FREIRE, P. Pedagogia da autonomia: Saberes necessários à prática educativa. 16 ed. Rio de Janeiro: Terra, 2000.

HERMÍNIO, C. I. Repensando as aulas de ciências nas séries iniciais. Disponível em: $<$ http://www1.fapa.com.br/cadernosfapa/php/home.php?pag=16>. Acessado em 30 de mar. de 2017.

HERNANDEZ, F. A organização do currículo por projeto de trabalho: O conhecimento é um caleidoscópio. Porto Alegre: Artes Médicas, 1998.

MILLAR, R. Um currículo de Ciências voltado para a compreensão por todos. Ensaio: Pesquisa em educação em ciências, v. 5, n. 2, p. 146-164. Disponível em: <https://doi.org/10.1590/1983-21172003050206>. Acessado em 30 de mar. de 2017.

MORAES, R; LIMA, V. Pesquisa em sala de aula: Tendências para a educação em novos tempos. 2 ed. Porto Alegre: Edipucrs, 2004.

MOREIRA, M.A. E BUCHWEITZ, B. Novas estratégias de ensino e aprendizagem: os mapas conceituais e o Vê epistemológico. Lisboa: Plátano Edições Técnicas, 1993.

PATTON, M. Qualitative evaluation and research methods. 4 ed. London: Sage. 2015. 
POZO, J.; CRESPO, M. A aprendizagem e o ensino de Ciências: do conhecimento cotidiano ao conhecimento científico. 5 ed. Porto Alegre: Artmed, 2009.

ROSE. ROSE National reports on organizing the ROSE survey. 2004. Disponível em: $<$ https://www.uv.uio.no/ils/english/research/projects/rose/partners/uk/org-reportscot.pdf>. Acessado em 30 de mar. de 2017.

SILVA, M. R. A. D. O clube de Ciências como lócus do ensino e aprendizagem. 2008. Dissertação (Mestrado em Ensino de Ciências e Matemática). UNICSUL. São Paulo, 2008.

SOUZA, N. A. de; BORUCHOVITCH, E. Mapas conceituais: estratégia de ensino/aprendizagem e ferramenta avaliativa. Educação em revista. v. 26, n. 3, p. 195217, 2010. Disponível em <http://www.scielo.br/scielo.php?script=sci_arttext\&pid=S0102-

46982010000300010\&lng= en\& nrm=iso >. Acesso em: 31 de mar. 2017. 